\title{
An Efficient Ascending-Bid Auction for Multiple Objects
}

\author{
Lawrence M. Ausubel* \\ University of Maryland
}

7 August 2002

(first draft: 8 November 1995)

\begin{abstract}
In multiple-object environments where individual bidders may demand more than one object, standard methods of auction generally result in allocative inefficiency. This paper proposes a new ascending-bid method for auctioning homogeneous goods, such as Treasury bills or communications spectrum. The auctioneer announces a current price, bidders report back the quantity demanded at that price, and the auctioneer raises the price. Objects are awarded to bidders at the current price whenever they are "clinched," and the process continues until the market clears. With pure private values, the proposed (dynamic) auction yields the same outcome as the (sealed-bid) Vickrey auction, but may be simpler for bidders to understand and has the advantage of assuring the privacy of the upper portions of bidders' demand curves. With interdependent values, the proposed auction may still yield efficiency, whereas the Vickrey auction fails due to a problem which could be described as the "Generalized Winner's Curse."
\end{abstract}

JEL No.: D44 (Auctions)

Keywords: Auctions, multi-unit auctions, efficient auctions, ascending auctions, Vickrey auctions

Send comments to:

Professor Lawrence M. Ausubel Department of Economics

University of Maryland

College Park, MD 20742-7211

ausubel@econ.umd.edu

301.405.3495

*I am extraordinarily grateful to Kathleen Ausubel and Peter Cramton for numerous helpful discussions. I also wish to thank Theodore Groves, Ronald Harstad, John Ledyard, Eric Maskin, Preston McAfee, Paul Milgrom, Philip Reny, Vernon Smith, Robert Wilson and four anonymous referees for useful feedback, comments, suggestions and explanations at various stages in the preparation of this paper. I appreciate valuable comments from participants and discussants at the Princeton University Conference on the Spectrum Auctions, the Universitat Pompeu Fabra Conference on Auctions, the North American Meetings of the Econometric Society, the American Economic Association Meetings, the Utah Winter Finance Conference, and the NSF Decentralization Conference, as well as seminar participants at numerous universities.

This paper is dedicated to William Vickrey (1914-1996). 
The auctions literature has provided us with two fundamental prescriptions guiding effective auction design. First, an auction should be structured so that the price paid by a player-conditional on winning — is as independent as possible of her own bids (William Vickrey, 1961). Ideally, the winner's price should depend solely on opposing participants' bids — as in the sealed-bid, second-price auction — so that each participant has full incentive to truthfully reveal her value for the good. Second, an auction should be structured in an open fashion that maximizes the information made available to each participant at the time she places her bids (Paul R. Milgrom and Robert J. Weber, 1982a). When there is a commonvalue component to valuation and when bidders' signals are affiliated, an open ascending-bid format may induce participants to bid more aggressively (on average) than in a sealed-bid format, since participants can infer greater information about their opponents' signals at the time they place their final bids.

In single-object environments, these dual prescriptions are often taken to imply the desirability of the English auction and to explain its prevalence (see, for example, the excellent surveys of R. Preston McAfee and John McMillan, 1987, and Milgrom, 1987). However, for auctions where bidders acquire multiple items, nobody appears to have before combined these two broad insights and taken them to their logical conclusion. The current article does precisely that: I propose a new ascending-bid auction format for multiple objects that literally takes heed of the two traditional prescriptions for auction design.

The starting point for understanding the design proposed herein is to consider the uniform-price auction. Recall that the classic English auction for a single object can be sensibly collapsed down to a sealed-bid, second-price auction. Analogously, most existing ascending-bid auction designs for identical objects can be sensibly collapsed down to the uniform-price auction, in which bidders simultaneously submit bids comprising demand curves, the auctioneer determines the clearing price, and all bids exceeding the clearing price are deemed winning bids at the clearing price. Unfortunately, the uniformprice auction possesses a continuum of equilibria yielding less than the competitive price (Wilson, 1979; Back and Zender, 1993), and indeed, with private information, every equilibrium of the uniform-price auction yields inefficient outcomes with positive probability (Ausubel and Cramton, 2002). The reason for inefficiency is that uniform pricing creates strong incentives for "demand reduction": a bidder will bid less than her value for a marginal unit, in order to depress the price that she pays for inframarginal units.

More extreme results are possible if the auction is explicitly sequential. Ausubel and Schwartz (1999) show that a two-bidder, alternating-bid version of the uniform-price ascending auction possesses a unique subgame perfect equilibrium. The first bidder bids the opening price on slightly more than half the units, the second bidder bids the next possible price on the remaining units, and the game ends. Thus, the allocation need not bear any connection to an efficient outcome and the price (one bid increment above the reserve price) need not bear any connection to a competitive price. While this prediction is admittedly extreme, it was almost perfectly borne out, empirically, in an October 1999 German spectrum auction. ${ }^{1}$

\footnotetext{
${ }^{1}$ As recounted by Jehiel and Moldovanu (2000), ten licenses for virtually homogeneous spectrum were offered to the four German mobile phone incumbents. In the first round of bidding, Mannesmann placed high bids of DM 36,360,000 per MHz on each of licenses 1-5 and high bids of DM 40,000,000 per MHz on each of licenses 6-10. In the second round of bidding, T-Mobil raised Mannesmann on licenses $1-5$ by bidding a price of 40,010,000 DM (the minimum bid increment was $10 \%$ ), while letting Mannesmann maintain the high bids on licenses 6-10. In the third round of bidding, no new bids were entered, and so the auction ended in two rounds with the two largest incumbents dividing the market almost equally at an apparently uncompetitive low price.
} 
By way of contrast, the (multi-unit) Vickrey auction is an effective static design when bidders with pure private values have tastes for consuming more than one object: Again, bidders submit sealed bids comprising demand curves, the auctioneer determines the clearing price, and all bids exceeding the clearing price are deemed winning bids. However, the price paid for each unit won is neither the amount of the bid nor the clearing price, but the opportunity cost of assigning this unit to the winning bidder. For discrete objects, if bidder $i$ is to be awarded $k$ objects, then she is charged the amount of the $k^{\text {th }}$ highest rejected bid (other than her own) for her first unit, the $(k-1)^{\text {st }}$ highest rejected bid (other than her own) for her second unit, $\ldots$, and the highest rejected bid (other than her own) for her $k^{\text {th }}$ unit. For $M$ divisible objects, Figure 1 depicts the outcome: $x_{i}(p)$ denotes bidder $i$ 's demand curve, $M-x_{-i}(p)$ denotes the residual supply after subtracting out the demands of all other bidders, $p^{*}$ denotes the market-clearing price if all bidders participate in the auction, and $p_{-i}^{*}$ denotes the market-clearing price in the absence of bidder $i$. The Vickrey auction awards a quantity of $x_{i}\left(p^{*}\right)$ to bidder $i$, and requires a payment equal to the area of the shaded region in Figure 1. Thus, each participant's payment (conditional upon winning a given quantity) is independent of her own bids, embodying the first prescription of auction design.

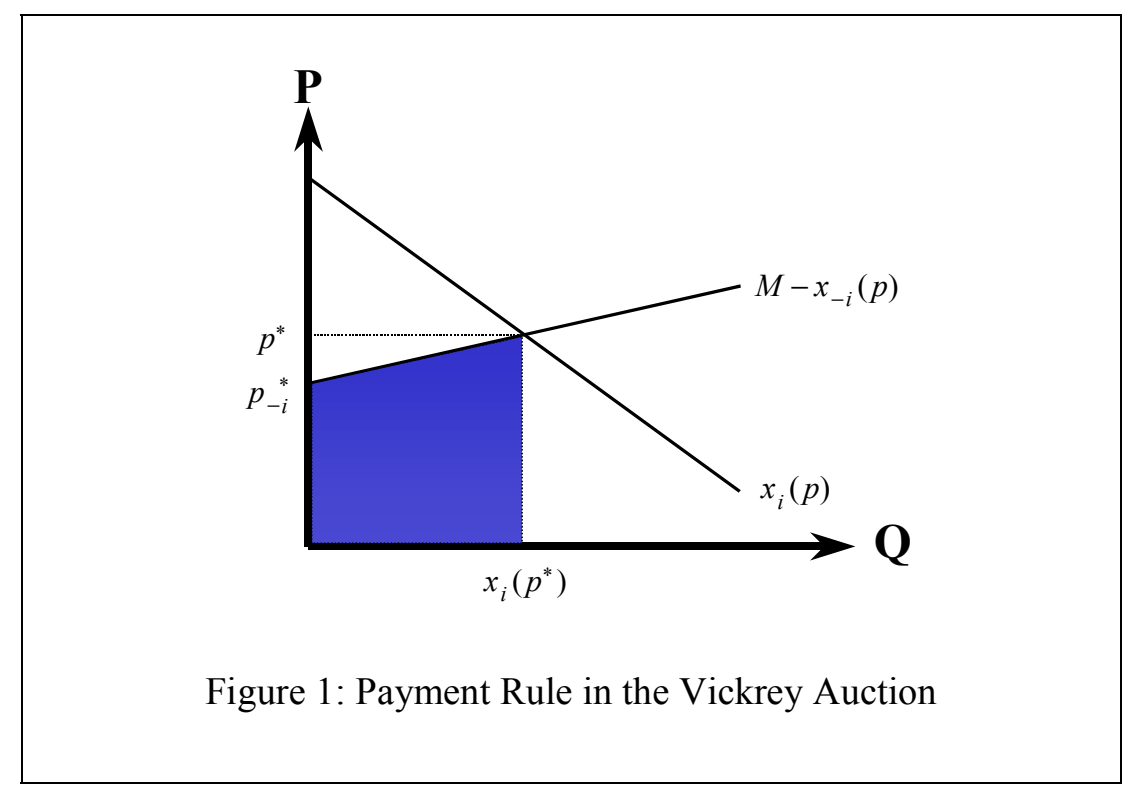

However, there would appear to be significant advantages if a multi-unit auction format could also reflect the second prescription of auction design. The principal questions under consideration may thus be stated:

Can the analogy between the English auction and the second-price auction be completed for multiple objects? In particular, when bidders have pure private values, does there exist a simple ascending-bid auction for homogeneous goods whose static representation is the (multi-unit) Vickrey auction? And, to the extent that the analogy can be completed, will the ascending-bid auction outperform the sealed-bid auction in interdependent values environments generalizing the Milgrom-Weber symmetric model?

This paper provides a substantial affirmative answer. A new ascending-bid auction is proposed, which operates as follows. The auctioneer calls a price, bidders respond with quantities, and the process iterates with increasing prices until demand is no greater than supply. However, a bidder's payment does not equal her final quantity times the final price. Rather, at each price $p$, the auctioneer determines 
whether, for any bidder $i$, the aggregate demand $x_{-i}(p)$ of bidder $i$ 's rivals is less than the supply $M$. If so, the difference is deemed "clinched," and any goods newly clinched are awarded to bidder $i$ at price $p$.

For example, suppose that five objects are available and that four bidders A, B, C and D initially bid for quantities of 3,2, 2 and 2, respectively. Suppose that bidders continue to bid these quantities until price $p$, when Bidder D reduces from 2 units to 0 , dropping out of the auction. While there continues to be excess demand, Bidder A's opponents now collectively demand only four units, while five are available. Bidder A therefore clinches one unit at price $p$, and the auction (for the remaining objects) continues.

In the new auction design, a bidder's payment for inframarginal units is effectively decoupled from her bids for marginal units, eliminating any incentive for demand reduction. Consequently, with private values, sincere bidding is an equilibrium, yielding the same efficient outcome as the Vickrey auction. Moreover, under incomplete information and a "full support" assumption, sincere bidding is the unique outcome of iterated weak dominance, just as sincere bidding is the unique outcome of weak dominance in the Vickrey auction. Thus, the following analogy holds:

The second-price auction is to the English auction, as the multi-unit Vickrey auction is to the ascending-bid auction proposed herein.

Furthermore, consider a symmetric setting in which bidders have constant marginal values that are interdependent in the sense that one bidder's value depends on her rivals' signals. (While restrictive, this model strictly generalizes the classic Milgrom and Weber framework.) Then, the new (dynamic) auction format outperforms the (static) Vickrey auction on efficiency. Moreover, there are at least two sets of examples within this model for which the dynamic auction raises higher expected revenues.

Simplicity or transparency to bidders should be viewed as one important attribute and advantage of the proposed auction. While the single-item Vickrey auction is well known, the multi-unit version proposed by Vickrey in the same 1961 article remains relatively obscure even among economists, and is hardly ever advocated for real-world use. One reason seems to be that many believe it is too complicated for practitioners to understand, even in the private values environment where the traditional theory finds no informational advantages to a dynamic auction over a static auction. ${ }^{2}$ By contrast, the ascending-bid design proposed here seems simple enough to be understood by any aficionado of baseball pennant races. This prediction appears to be borne out in the early experimental evidence (see the Conclusion).

Privacy-preservation of the winning bidders' values is a second attribute and advantage of the new ascending-bid auction. Noting that English auctions are quite prevalent in the real world while sealed-bid second-price auctions are comparatively rare, Michael H. Rothkopf, Thomas J. Teisberg, and Edward P. Kahn (1990) offer a possible explanation: bidders will be reluctant to truthfully reveal their private values in an auction if either there may be cheating by the auctioneer or there will be subsequent auctions or negotiations in which the information revealed can be used against them. ${ }^{3}$ Such considerations

\footnotetext{
${ }^{2}$ Indeed, the subtlety of the Vickrey auction has been a problem even in experimental auction studies involving merely a single object. John H. Kagel, Ronald M. Harstad and Dan Levin (1987) found that bidders with affiliated private values behaved closer to the dominant strategy in ascending-clock auctions than in sealed-bid second-price auctions.

${ }^{3}$ Richard Engelbrecht-Wiggans and Charles M. Kahn (1991) and Rothkopf and Harstad (1995) also provide models emphasizing the importance of protecting the privacy of winners' valuations.
} 
favor ascending-bid auctions, since winning bidders need not reveal their entire demand curves, but only the portion below the winning price. ${ }^{4}$

Robustness to interdependent valuations is a third possible advantage of my auction. In the symmetric model with flat demands and interdependent values, let $M$ denote the supply of objects and let $\lambda_{i}$ denote the number of objects desired by bidder $i$. If $\lambda_{i} \equiv \lambda$ and $M / \lambda$ is an integer, efficient equilibria occur in both the static and dynamic auctions, but the seller's expected revenues are greater in the dynamic auction, replicating Milgrom and Weber's point. For the remaining parameter values, efficient equilibria are impossible in the static auction, but they are present in the ascending auction.

The following articles constitute a less-than-exhaustive list of related research. Milgrom and Weber (1982b, pp. 4-5) introduce the uniform-price ascending-bid auction when bidders have unit demands and there are multiple identical objects, and extend their (1982a) analysis of symmetric environments with affiliated information to this multi-unit context. Eric S. Maskin (1992) demonstrates that, even for single-item auctions with asymmetric bidders and interdependent information, the English auction is more likely to yield efficiency than the second-price auction. Maskin and John G. Riley (1989) examine optimal auctions for multiple identical objects in an independent private values setting. Alexander S. Kelso and Vincent P. Crawford (1982), Gabrielle Demange, David Gale, and Marilda Sotomayor (1986), Sushil Bikhchandani and John W. Mamer (1997), Bikhchandani (1999), Faruk Gul and Ennio Stacchetti $(1999,2000)$ and Milgrom (2000) study various auction procedures for multiple items and their relationship with Walrasian prices under complete information. Bikhchandani and Joseph M. Ostroy (2001) and Bikhchandani et al. (2001) formulate the auction problem as a linear programming problem and reinterpret the auction design herein as a primal-dual algorithm. Motty Perry and Philip J. Reny $(2001,2002)$ study more general homogeneous goods environments with interdependent values and extend the auction design herein to such environments. Partha Dasgupta and Maskin (2000) define a sealed-bid auction procedure designed to attain efficiency with heterogeneous items. Vijay Krishna and Perry (1998) study the Vickrey auction in an independent private values setting.

The paper is organized as follows. Section 1 informally describes the new ascending-bid auction via an illustrative example. Section 2 presents the formal model. Section 3 analyzes the private values case, demonstrating that sincere bidding is an equilibrium and that, under incomplete information and a "full support" assumption, it is the unique outcome of iterated weak dominance. Section 4 treats, in a continuous-time formulation, a symmetric model of interdependent values, where bidders have affiliated signals and exhibit constant marginal values. Section 5 concludes. Proofs are relegated to the Appendix.

\footnotetext{
${ }^{4}$ For example, suppose that the government sells a spectrum license valued by the highest bidder at $\$ 1$ billion but by the secondhighest bidder at only $\$ 100$ million, in a sealed-bid second-price auction. There are at least three potential problems here. First, there is likely to be a public relations disaster, as the ensuing newspaper headlines read, "Billion-dollar communications license given away for 10 cents on the dollar." Second, there may be a problem of seller cheating: after opening the submitted bids, the auctioneer may ask his friend, "Mind if I insert a bogus \$997 million bid in your name? It won't cost you anything, but it will earn me a lot of money." Third, revelation of the winner's billion-dollar value may imperil her subsequent bargaining position with equipment suppliers. By contrast, an English auction avoids these problems, revealing only that the high bidder's value exceeded \$100 million. (See also the nice discussion of this point in McMillan, 1994, especially at p. 148.)
} 


\section{An Illustrative Example}

I will illustrate my proposal for an ascending-bid, multi-unit auction with an example loosely patterned after the first U.S. spectrum auction, the Nationwide Narrowband Auction. There are five identical licenses for auction. ${ }^{5}$ Bidders have taste for more than one license, but each is limited to winning at most three licenses. ${ }^{6}$ There are five bidders with values in the relevant range, and their marginal values are given as in Table 1 (where numbers are expressed in millions of dollars):

\begin{tabular}{|l|c|c|c|c|c|}
\hline & Bidder A & Bidder B & Bidder C & Bidder D & Bidder E \\
\hline Marginal Value (1 unit) & 123 & 75 & 125 & 85 & 45 \\
\hline Marginal Value (2 units) & 113 & 5 & 125 & 65 & 25 \\
\hline Marginal Value (3 units) & 103 & 3 & 49 & 7 & 5 \\
\hline
\end{tabular}

Table 1: Bidder Valuations in Illustrative Example

For example, if Bidder A were to purchase two licenses at prices of 75 each, her total utility from the transaction would be computed by: $u_{A}(1)+u_{A}(2)-75-75=123+113-160=86$. In this example, bidders are presumed to possess complete information about their rivals' valuations.

The proposed auction is operated as an ascending-clock auction. The auctioneer announces a price, $p$, and each bidder $i$ responds with a quantity, $q_{i}(p)$. The auctioneer then calculates the aggregate demand and increases the price until the market clears. Payments are calculated according to a "clinching" rule. Suppose that the auction begins with the auctioneer announcing a price of $\$ 10$ million $(+\varepsilon)$. Bidders A-E, if bidding sincerely according to the valuations of Table 1, would respond with demands of 3, 1, 3, 2 and 2, respectively. The aggregate demand of 11 exceeds the available supply of 5 , so the auction must proceed further. Assume that the auctioneer increases the price continuously. Bidder E reduces his quantity demanded from 2 to 1 at $\$ 25$ million, Bidder E drops out of the auction completely at $\$ 45$ million and Bidder $\mathrm{C}$ reduces his quantity demanded from 3 to 2 at $\$ 49$ million, yielding:

\begin{tabular}{|c|c|c|c|c|c|}
\hline Price & Bidder A & Bidder B & Bidder C & Bidder D & Bidder E \\
\hline 49 & 3 & 1 & 2 & 2 & 0 \\
\hline
\end{tabular}

The aggregate demand, now 8, continues to exceed the available supply of 5 , so the price must rise further. When the price reaches $\$ 65$ million, Bidder D reduces her demand from 2 to 1 , but the aggregate demand of 7 continues to exceed the available supply of 5 :

\footnotetext{
${ }^{5}$ In actuality, the FCC's Nationwide Narrowband Auction offered ten licenses, of three different types: five (essentially identical) $50 / 50 \mathrm{kHz}$ paired licenses; three (essentially identical) $50 / 12.5 \mathrm{kHz}$ paired licenses; and two (essentially identical) $50 \mathrm{kHz}$ unpaired licenses. For an extraordinarily cogent discussion of the Nationwide Narrowband Auction, see Cramton (1995).

${ }^{6}$ In actuality, the FCC limited bidders to acquiring three licenses, either through the auction or through resale. Observe that the total number of licenses is not an integer multiple of each bidder's limitation on purchases, so with incomplete information, the inefficiency result of Ausubel and Cramton (2002, Theorem 1) is applicable, even if the marginal values for the first, second, and third licenses are equal.
} 


\begin{tabular}{|c|c|c|c|c|c|}
\hline Price & Bidder A & Bidder B & Bidder C & Bidder D & Bidder E \\
\hline 65 & 3 & 1 & 2 & 1 & 0 \\
\hline
\end{tabular}

However, let us examine this situation carefully from Bidder A's perspective. The demands of all bidders other than Bidder $A$ (i.e., $1+2+1+0$ ) total only 4 , while 5 licenses are available for sale. If Bidders B-E bid monotonically, Bidder A is now mathematically guaranteed to win at least one license. In the language of this paper (and in the standard language of American sports writing), Bidder A has clinched winning one unit. The rules of the auction take this calculation quite literally, by awarding each bidder any units that she clinches, at the clinching price. Bidder A thus wins a license at $\$ 65$ million.

Since there is still excess demand, price continues upward. With continued sincere bidding relative to the valuations in Table 1 , the next change in demands occurs at a price of $\$ 75$ million. Bidder $\mathrm{B}$ drops out of the auction, but the aggregate demand of 6 continues to exceed the available supply of 5 :

\begin{tabular}{|c|c|c|c|c|c|}
\hline Price & Bidder A & Bidder B & Bidder C & Bidder D & Bidder E \\
\hline 75 & 3 & 0 & 2 & 1 & 0 \\
\hline
\end{tabular}

However, again examine the situation from Bidder A's perspective. Her opponents collectively demand only $0+2+1+0=3$ units, whereas 5 units are available. It may now be said that she has clinched winning 2 units: whatever happens now (provided that her rivals bid monotonically), she is certain to win at least 2 units. Hence, the auction awards a second unit to Bidder A at the new clinching price of $\$ 75$ million. By the same token, let us examine this situation from Bidder C's perspective. Bidder C's opponents collectively demand only $3+0+1+0=4$ units, whereas 5 units are available. He has now clinched winning 1 unit: whatever happens now (provided that his rivals bid monotonically), he is certain to win at least 1 unit. Hence, the auction awards one unit to Bidder $\mathrm{C}$ at a price of $\$ 75$ million.

There continues to be excess demand until the price reaches $\$ 85$ million. Bidder D then drops out of the auction, yielding:

\begin{tabular}{|c|c|c|c|c|c|}
\hline Price & Bidder A & Bidder B & Bidder C & Bidder D & Bidder E \\
\hline 85 & 3 & 0 & 2 & 0 & 0 \\
\hline
\end{tabular}

At $\$ 85$ million, the market clears. Bidder A, who had already clinched a first unit at $\$ 65$ million and a second at $\$ 75$ million, wins a third unit at $\$ 85$ million. Bidder $\mathrm{C}$, who had already clinched a first unit at $\$ 75$ million, wins a second unit at $\$ 85$ million. In summary, we have the following auction outcome:

\begin{tabular}{|c|c|c|c|c|c|}
\hline & Bidder A & Bidder B & Bidder C & Bidder D & Bidder E \\
\hline Units Won & 3 & 0 & 2 & 0 & 0 \\
\hline Payments & $65+75+85$ & 0 & $75+85$ & 0 & 0 \\
\hline
\end{tabular}

Observe that the outcome is efficient: the auction has put the licenses in the hands of bidders who value them the most. Also observe that the new (dynamic) auction has exactly replicated the outcome of 
the (sealed-bid) Vickrey auction. Bidder A won her first unit at the third-highest rejected bid, her second unit at the second-highest rejected bid and her third unit at the highest rejected bid. Bidder $\mathrm{C}$ won his first unit at the second-highest rejected bid and his second unit at the highest rejected bid.

Next, let us reexamine the example of Table 1, in order to see what outcome would have ensued if we had instead applied a uniform-pricing rule. As before, the auctioneer calls prices, bidders respond with quantities, and the price is incremented until $p^{*}$ is reached at which there is no excess demand. However, in a uniform-price ascending-clock auction, any bidder $i$ assigned a final quantity $x_{i}^{*}$ pays the amount $p^{*} x_{i}^{*}$. Then, there exists an equilibrium in which the auction concludes at a price of $\$ 75$ million and with an inefficient allocation. More strikingly, if the example is perturbed so that $\operatorname{Pr}\left\{u_{A}(3)=k\right\}=\varepsilon$, for every $k=76, \ldots, 84,86$ and for small but positive $\varepsilon$, this inefficient equilibrium is the unique outcome of iterated weak dominance. By contrast, the same criterion - applied to the ascending auction with a clinching rule — selects the sincere bidding equilibrium (see Theorem 2 for the general argument).

To analyze the perturbed example, let us suppose that the prior bidding has been sincere and consider the game at a price of $\$ 75$ million. Bidders A-E's standing bids are 3,1,2,1 and 0, respectively. Observe that it is weakly dominant for Bidder D to maintain a quantity of 1 for all prices less than $\$ 85$ million and to then reduce her quantity to 0 (since, with the perturbed $u_{A}(3)$, Bidder $\mathrm{A}$ has a positive probability of reducing from 3 to 2 at any price between $\$ 75$ and $\$ 85$ million). Similarly, it is weakly dominant for Bidder $\mathrm{B}$ to reduce her quantity to 0 at $\$ 75$ million. Following elimination of these strategies for Bidders D and B, Bidder A (if she has $u_{A}(3)=85$ ) has two candidate optimal actions: she can continue to bid sincerely, winning 3 items at a price of $\$ 85$ million (giving her surplus of $\$ 84$ million); or she can reduce her demand, thereby immediately ending the auction and winning 2 items at a price of $\$ 75$ million (giving her surplus of $\$ 86$ million). Thus, uniform pricing uniquely gives a final price of $\$ 75$ million and an inefficient allocation of goods of $(2,0,2,1,0)$ as the outcome of iterated weak dominance. ${ }^{7}$ By contrast, a clinching rule uniquely yields an efficient allocation (Theorem 2); and despite giving away one license at a bargain $\$ 65$ million in this example, yields $\$ 10$ million more in revenue. ${ }^{8}$

Most other conventional auction approaches also yield inefficient equilibria when applied to the example of Table 1. One approach is to sell the identical objects, one after another, by successive singleitem English auctions. This, for example, is how Sotheby's attempted to auction seven satellite transponders in November 1981 (see Milgrom and Weber, 1982b). Observe that there is then a tendency toward intertemporal arbitrage, which lends the auction process a uniform-price character.

A more sophisticated approach is the simultaneous multiple-round auction (SMR) used by the Federal Communications Commission to assign spectrum licenses. ${ }^{9}$ Bidders successively name prices on individual items; and the bidding is not deemed to have concluded for any single item until it stops for all items. In such a format, there is an even stronger tendency toward arbitrage, so that similar items sell for

\footnotetext{
${ }^{7}$ In the complete iterated weak dominance argument (omitted here, for brevity), we would argue also that neither Bidder A nor C reduces demand below 2 and that neither Bidder B nor D reduces demand below 1 before the price reaches $\$ 75$ million.

${ }^{8}$ The revenue ranking of the alternative ascending-bid auction versus the uniform-price ascending-bid auction is ambiguous.

${ }^{9}$ See Cramton (1995) and Milgrom (2000).
} 
similar prices. Most strikingly, in the real-world Nationwide Narrowband Auction on which Example 1 was patterned, the five virtually identical $50 / 50 \mathrm{kHz}$ paired licenses each sold for exactly $\$ 80,000,000{ }^{10}$ subsequent FCC auctions have displayed only minor amounts of price discrepancy for similar licenses.

To the extent that prices are arbitraged under either of these approaches, essentially the same inefficiencies should result as in the uniform-price ascending-bid auction. If either five successive singleitem auctions or the FCC's SMR auction were used in Example 1, Bidder A does best by bidding only up to a price of $\$ 75$ million. With the five successive auctions, Bidder A might consequently lose the first three auctions to Bidder C (2 units) and Bidder D (1 unit); however, with the high marginal values out of the way, Bidder A assures herself winning the last two auctions at $\$ 75$ million each. Similarly, with the SMR auction, two of Bidder A's \$75 million bids would not be outbid.

Finally, let us consider the two sealed-bid auction formats that have generally been used for U.S. (and other governments') Treasury auctions: the pay-as-bid auction and the uniform-price auction. ${ }^{11}$ As applied to Example 1, these two auctions again have the property that all equilibria in undominated strategies are inefficient. For the uniform-price auction, this follows the same argument as before: in an efficient equilibrium in undominated strategies, Bidder D's bid of $\$ 85$ million and Bidder B's bid of $\$ 75$ million need to be rejected. Bidder A calculates that she can improve her demand so that she wins only two items. For the pay-as-bid auction, we can apply almost identical reasoning: in an efficient equilibrium, the winning bids must all be at least $\$ 85$ million; otherwise, unsatisfied Bidder D could profitably deviate. But Bidder A could then substitute two bids of $\$ 75$ million $(+\varepsilon)$ for her three bids of $\$ 85$ million, improving her payoff. ${ }^{12}$

\section{The Model}

There are at least two useful ways to formulate a mathematical model of the new auction. In the first, the price clock advances in discrete (e.g., integer) steps, and bidders' marginal valuations are taken from the same set of discrete (e.g., integer) values. In the second, the price clock operates in continuous time, enabling full separation of bidders' continuous signals. Sections 2 and 3 will focus on the first, simpler formulation. The model is sufficiently rich to provide a relatively comprehensive treatment of private values. Moreover, most practical implementations of auctions include some amount of discreteness, giving rise to a positive probability of ties, and the analysis of the discrete formulation includes a rather complete treatment of ties. (Continuous-time games obviate this problem, since a tie is then a zero-probability event.) Section 4 will then introduce and study the second formulation, which is required for a treatment of efficiency using the standard (continuous) models of interdependent values.

\footnotetext{
${ }^{10}$ See Cramton (1995). Moreover, bidders could submit any integer prices in excess of a (nonbinding) minimum bid increment.

${ }^{11}$ These formats are defined and studied in detail in Ausubel and Cramton (2002).

12 The pay-as-bid and uniform-price auctions also possess efficient equilibria-but only if we allow bidders to use weaklydominated strategies. For Example 1, following Bikhchandani (1999), it is an efficient equilibrium of the pay-as-bid auction if Bidder A submits three (winning) bids of $85(+\varepsilon)$, Bidder $\mathrm{C}$ submits two (winning) bids of $85(+\varepsilon)$, Bidder D submits a (losing) bid of 85 , and some bidder submits an additional (losing) bid, $b$, of at least 76 . However, observe that this requires that the additional losing bid, $b$, exceed the bidder's marginal value. If $b<76$, Bidder A can profitably deviate by instead bidding only $b+\varepsilon$, thereby settling for only two objects. Similar reasoning applies to the uniform-price auction.
} 
A seller wishes to allocate $M$ homogeneous goods among $n$ bidders, $N \equiv\{1, \ldots, n\}$. Each bidder $i$ may be assigned any quantity $x_{i}$ in the consumption set $X_{i}$, subject to the feasibility constraint that $\sum_{i=1}^{n} x_{i} \leq M$. We simultaneously treat two interesting cases: $X_{i}=\left[0, \lambda_{i}\right]$, so that the good is perfectly divisible; or $X_{i}=\left\{0,1,2, \ldots, \lambda_{i}\right\}$, so that the good is discrete. (In either case, $0<\lambda_{i} \leq M$.) Bidder $i$ 's utility is assumed to be quasilinear, equaling her pure private value, $U_{i}\left(x_{i}\right)$, for the quantity $x_{i}$ she receives less the total payment, $y_{i}$, that she is obligated to pay: $U_{i}\left(x_{i}\right)-y_{i}$. The value $U_{i}(\bullet)$ is assumed to be the integral of a marginal value $u_{i}(\bullet)$, and so $U_{i}\left(x_{i}\right)=\int_{0}^{x_{i}} u_{i}(q) d q$. Each bidder's marginal value function, $u_{i}(\bullet)$, may be publicly known - making this a game of complete information — or privately knownmaking this a game of incomplete information. In either case, we assume that all marginal values are uniformly bounded above by $\bar{u}>0$ and below by zero. The marginal value $u_{i}:\left[0, \lambda_{i}\right] \rightarrow \mathbb{Z}$ is assumed to be weakly decreasing in $q$ and integer valued. Thus, bidders exhibit diminishing marginal utilities, Walrasian price(s) are guaranteed to exist, and the lowest Walrasian price is an integer between 0 and $\bar{u}$.

The auction is modeled as a dynamic game in discrete time. At each time $t=0,1,2, \ldots, T$, the price $p^{t}=t$ is communicated to (or already known by) the $n$ bidders, and each bidder $i$ responds by bidding a quantity $x_{i}^{t} \in X_{i}$. The presentation is simplest if bidders are constrained to bid monotonically: ${ }^{13}$

$$
\text { Monotone activity rule: } x_{i}^{t} \leq x_{i}^{t-1} \text {, for all } i=1, \ldots, n \text { and all } t=1, \ldots, T \text {. }
$$

The final time, $T$, after which the auction exogenously ends, is selected so as not to bind, i.e., $T>\bar{u}$. We define the vector of cumulative clinches, $\left\{C_{i}^{t}\right\}_{i=1}^{n}$, at time $t$ by:

$$
C_{i}^{t}=\max \left\{0, M-\sum_{j \neq i} x_{j}^{t}\right\}, \text { for all } t=0, \ldots, L-1 \text { and } i=1, \ldots, n \text {, and }
$$

$$
C_{i}^{L}=x_{i}^{*} \text {, where } L \text { is the round in which the auction closes and } x_{i}^{*} \text { is the assignment to bidder } i \text {. }
$$

We define the vector of current clinches, $\left\{c_{i}^{t}\right\}_{i=1}^{n}$, at time $t$ as the difference between the cumulative clinches at time $t$ and the cumulative clinches at time $t-1$, i.e.:

$$
c_{i}^{t}=C_{i}^{t}-C_{i}^{t-1}, \text { for } t=1, \ldots, L \text { and } c_{i}^{0}=C_{i}^{0}, \text { for all } i=1, \ldots, n .
$$

Bidder $i$ 's bid, $x_{i}^{t}$, is also constrained to satisfy $x_{i}^{t} \geq C_{i}^{t-1}$, that is, bidder $i$ may bid no less than her prior cumulative clinches.

Suppose that the auction is fully subscribed at the starting price: $\sum_{i=1}^{n} x_{i}^{0} \geq M$. Then the auction continues until such time that there is no excess demand, or until the exogenous ending time $T$ is reached, whichever occurs sooner. Thus, after each time $t=0, \ldots, T$, the auctioneer determines whether $\sum_{i=1}^{n} x_{i}^{t} \leq M$. If this inequality is satisfied, then the current time $t$ is designated the last time of the auction: we write $L=t$. Each bidder $i$ is assigned a final quantity $x_{i}^{*}$ that satisfies $x_{i}^{L} \leq x_{i}^{*} \leq x_{i}^{L-1}$ and $\sum_{i=1}^{n} x_{i}^{*}=M \cdot{ }^{14}$ If this inequality is not satisfied but $t=T$, the exogenous ending time, then the current

\footnotetext{
${ }^{13}$ In real-world auctions, activity rules of this type are often imposed. The concern is that without such an activity rule, a bidder with serious interest in the items for auction may choose to wait to bid, as a "snake in the grass," until the auction appears nearly ready to close. The activity rule prevents a bidder from concealing her true intentions until late in the auction, by requiring her to bid on a given quantity early in the auction in order to preserve the right to bid on this quantity late in the auction.

${ }^{14}$ If $\sum_{i=1}^{n} x_{i}^{L}<M$, then there is a need for rationing some of the bidders in order to sell the entire quantity $M$. So long as it is consistent with $x_{i}^{L} \leq x_{i}^{*} \leq x_{i}^{L-1}$ and $\sum_{i=1}^{n} x_{i}^{*}=M$, the rationing rule may be specified relatively arbitrarily, but it must satisfy
} 
time $T$ is designated the last time of the auction: we write $L=T$. Each bidder $i$ is assigned a final quantity $x_{i}^{*}$ that satisfies $x_{i}^{*} \leq x_{i}^{L}$ and $\sum_{i=1}^{n} x_{i}^{*}=M .{ }^{15}$ Finally, if there remains excess demand and $t<T$, the auction game proceeds to time $t+1$ (with associated price $p^{t+1}$ ) and the process repeats.

The payment rule is that the payment for each unit is the price at which it is clinched. In general (including continuous time) games, let $p(t)$ denote the price at time $t$ and let $C_{i}(t)$ denote the cumulative clinches based on the bids at time $t$. Then bidder $i$ 's total payment is the following Stieltjes integral:

$$
y_{i}=\int_{0}^{L} p(t) d C_{i}(t) .
$$

In the discrete-time notation of the current section, the payment equation (5) may equivalently be written:

$$
y_{i}=\sum_{t=0}^{L} p^{t} c_{i}^{t}
$$

However, if $\sum_{i=1}^{n} x_{i}^{0}<M$, then each bidder $i$ is assigned the quantity $x_{i}^{0}$ at the starting (zero) price.

A full specification of an ascending-bid auction game also requires some precision in stipulating the informational assumptions and the activity rules, as different informational assumptions and activity rules potentially lead to different outcomes. Let $h^{t} \equiv\left\{x_{1}^{t^{\prime}}, \ldots, x_{n}^{t^{\prime}}\right\}_{t^{\prime}<t}$ denote the history of play prior to time $t$ and let $h_{i}^{t}$ denote the summary of the history that is made observable to bidder $i$ (above and beyond her own prior bids). The following are three of the most interesting available informational rules:

FULL BID INFORMATION: The summary of the history observable to bidder $i$ is: $h_{i}^{t}=\left\{x_{1}^{t^{\prime}}, \ldots, x_{n}^{t^{\prime}}\right\}_{t^{\prime}<t}$, i.e., the complete history of all bids by all bidders.

AGGREGATE BID INFORMATION: The summary of the history observable to bidder $i$ is: $h_{i}^{t}=\left\{\sum_{j=1}^{n} x_{j}^{t^{t}}\right\}_{t^{\prime}<t}$, i.e., the complete history of the aggregate demand of all bidders.

NO BID INFORMATION: The summary of the history observable to bidder $i$ is: $h_{i}^{t}=1$, if $\sum_{j=1}^{n} x_{j}^{t-1}>M$, and 0 , otherwise, i.e., whether the auction is still open.

Given the informational assumption chosen, let $H_{i}^{t}$ denote the set of all possible histories observable to bidder $i$ at time $t$. In each of the theorems below, if the informational assumption is not otherwise specified, then the result holds for all three informational rules.

A strategy $\sigma_{i}:\{0, \ldots, T\} \times H_{i}^{t} \rightarrow X_{i}$ of player $i(i=1, \ldots, n)$ is any function of times and observable histories to quantities that is consistent with the bidding constraints, and the strategy space $\Sigma_{i}$ is the set of all such functions $\sigma_{i}\left(t, h_{i}^{t}\right)$. The information structure of the auction game may be one of complete or incomplete information regarding opposing bidders' valuations. With complete information, each bidder is fully informed of the functions $\left\{U_{j}(\bullet)\right\}_{j=1}^{n}$, and (if there is also full bid information) the

the following monotonicity property: if $x_{i}^{L}<x_{i}^{L-1}$, then the expected quantity $E\left[x_{i}^{*}\right]$ assigned to bidder $i$ must be strictly greater than her final bid $x_{i}^{L}$, and if the final bid $x_{i}^{L}$ of bidder $i$ is increased, while holding the final bids $x_{-i}^{L}$ of all opposing bidders fixed, then the (probability distribution on the) quantity $x_{i}^{*}$ assigned to bidder $i$ must increase.

${ }^{15}$ The rationing rule may be specified relatively arbitrarily, but it must satisfy the following monotonicity property: if the final bid $x_{i}^{L}$ of bidder $i$ is increased, while holding the final bids $x_{-i}^{L}$ of all opposing bidders fixed, then the (probability distribution on the) quantity $x_{i}^{*}$ assigned to bidder $i$ must increase. 
appropriate equilibrium concept is subgame perfect equilibrium. With incomplete information and pure private values, each bidder $i$ is informed only of her own valuation function $U_{i}(\bullet)$ and of the joint probability distribution $F(\bullet)$ from which the profile $\left\{U_{j}(\bullet)\right\}_{j=1}^{n}$ is drawn. The equilibrium concept that will then be used is ex post perfect equilibrium, which requires that the strategy specified for each bidder at each node of the auction game would remain optimal if the bidder were to learn her opponents' types:

EX POST PERFECT EQUILIBRIUM. The strategy $n$-tuple $\left\{\sigma_{i}\right\}_{i=1}^{n}$ is said to comprise an ex post perfect equilibrium if for every time $t$, following any history $h^{t}$, and for every realization $\left\{U_{i}\right\}_{i=1}^{n}$ of private information, the $n$-tuple of continuation strategies $\left\{\sigma_{i}\left(\bullet, \bullet \mid t, h_{i}^{t}, U_{i}\right)\right\}_{i=1}^{n}$ constitutes a Nash equilibrium of the game in which the realization of $\left\{U_{i}\right\}_{i=1}^{n}$ is common knowledge.

Alternatively, we could have explicitly defined beliefs for each bidder, and stated the theorems of this paper in terms of the perfect Bayesian equilibrium concept. ${ }^{16}$ (Indeed, the results in Section 4 involving interdependent valuations will utilize perfect Bayesian equilibrium.) However, stating the private values results in their current form gives them a number of additional desirable properties, e.g., the results are independent of the underlying distributions of bidders' types (see Maskin, 1992, and Perry and Reny, 2001, 2002). The results as stated also encompass the complete-information version of the model, as $e x$ post perfect equilibrium then reduces to the familiar equilibrium concept of subgame perfect equilibrium.

\section{Results with Private Values}

This section provides the private values results of the paper. Sincere bidding is an ex post perfect equilibrium of the model of Section 2. Furthermore, under incomplete information and a "full support" assumption, it is the unique outcome of iterated weak dominance. We begin by defining sincere bidding, which informally means "you just bid what you think it is worth":

DEFINITION 1. The sincere demand of bidder $i$ at price $p$ is: $Q_{i}(p) \equiv \inf \left\{\underset{x_{i} \in X_{i}}{\arg \max }\left\{U_{i}\left(x_{i}\right)-p x_{i}\right\}\right\}$. Sincere bidding is the strategy in which bidder $i$ bids her sincere demand at every time $t$ and after every history $h_{i}^{t}$, subject to the constraints posed by the monotone activity rule and her previous clinches: ${ }^{17}$

$$
x_{i}^{t}=\min \left\{x_{i}^{t-1}, \max \left\{Q_{i}\left(p^{t}\right), C_{i}^{t-1}\right\}\right\} \text {, for all } t=1, \ldots, T \text {, and } x_{i}^{0}=Q_{i}\left(p^{0}\right) .
$$

For example, given the illustrative valuations of Bidder $\mathrm{D}$ in Table 1, the sincere bid is: $x_{D}^{t}=3$, for $t=0, \ldots, 6 ; \quad x_{D}^{t}=2$, for $t=7, \ldots, 64 ; \quad x_{D}^{t}=1$, for $t=65, \ldots, 84 ; \quad$ and $\quad x_{D}^{t}=0$, for $t=85, \ldots, T$. This, however, assumes that the constraint $C_{D}^{t-1} \leq x_{D}^{t} \leq x_{D}^{t-1}$ is not binding due to the history of play in the auction. Sincere bidding is specified in Definition 1 so that the bidder never bids more than her quantity in the previous period and never bids less than the quantity that she has already clinched.

\footnotetext{
${ }^{16}$ We would begin by specifying that, after every history, each player $i$ has posterior beliefs, denoted $\mu_{i}\left(\bullet \mid t, h_{i}^{t}, U_{i}\right)$, over opponents' utility functions, $U_{-i}(\bullet) \equiv\left\{U_{j}(\bullet)\right\}_{j \neq i}$. The $n$-tuple $\left\{\sigma_{i}, \mu_{i}\right\}_{i=1}^{n}$ is then defined to comprise a perfect Bayesian equilibrium if the strategies $\sigma_{i} \in \Sigma_{i}$, if the beliefs $\mu_{i}$ are updated by Bayes' rule whenever possible, and if following any history $h^{t}$ of play prior to time $t, \sigma_{i}$ is a best response (given beliefs) for every player $i$ in the continuation game against $\left\{\sigma_{j}\right\}_{j \neq i}$

${ }^{17}$ Given a monotone activity rule, there is never any bite to the further constraint that a bidder cannot bid for fewer units than she has already clinched. (Attempting to do so would automatically trigger the last round of the auction, and the assignment rule would then already assure that the bidder receives as many units as she has clinched; see also footnote 14.) However, imposing the constraint in Eq. (7) is nevertheless useful for providing a clean statement to Theorem 2.
} 
Note that the assignment of goods in the auction has been specified (see the text near footnote 14) in such a way that bidder $i$ may be required to purchase more than $x_{i}^{*}>x_{i}^{L}$ units at price $p^{L}$ (that is, a larger number of units than she bid for at that price - albeit no larger a number than $x_{i}^{L-1}$, the number she bid for at the previous price). Nevertheless, observe that, given the sincere bidding strategy specified in Definition 1, there is never any ex post regret. Any time $t$ in which a sincere bidder $i$ reduces her bid, she is indifferent between receiving her prior bid $x_{i}^{t-1}$ and her current bid $x_{i}^{t}$. For example, using the strategy in the previous paragraph, Bidder D could potentially win 2 units at a price of 65 , even though $x_{D}^{65}=1$. However, her marginal value equals 65, so she is in fact indifferent between winning 1 or 2 units at 65 .

We are now ready to state our first theorem. All of the theorems are proved in the Appendix.

THEOREM 1. In the alternative ascending-bid auction with private values, sincere bidding by all bidders is an ex post perfect equilibrium, ${ }^{18}$ yielding the efficient outcome of the Vickrey auction. Furthermore, with no bid information, sincere bidding is a weakly dominant strategy for every bidder after every history.

With full or aggregate bid information, sincere bidding is not necessarily a dominant strategy. For example, suppose that for some bizarre reason, bidder $j$ uses the strategy of maintaining $x_{j}^{t}=x_{j}^{0}$ so long as $x_{i}>K$, for some positive constant $K$, but of dropping to $x_{j}^{t+1}=0$ in the first period following that $x_{i}^{t} \leq K$. Then it is possible that bidder $i$ may improve her payoff by reducing her demand to $K$ at a price $p$ where her marginal utility, $u_{i}(K)$ still exceeds $p$. However, the next theorem eliminates this possibility by iterated weak dominance. Under incomplete information, make the following additional assumption:

DEFINITION 2: For any nonnegative integer $k$, let $\Phi(k)$ denote the set of all weakly decreasing functions $\varphi: X_{i} \rightarrow\{0, \ldots, k\}$. In the private values model with incomplete information, bidder $j$ is said to satisfy the full support assumption if there exists $\bar{u}_{j} \geq 0$ such that the probability distribution from which bidder $j$ 's marginal value function $u_{j}(\bullet)$ is drawn has support equal to the full set $\Phi\left(\bar{u}_{j}\right){ }^{19}$

The role of the full support assumption is to guarantee that, conditional on a sincere bid, $x_{j}(t)$, at time $t$, there is both a positive probability that the next sincere bid satisfies $x_{j}(t+1)>x_{j}(t)-\varepsilon$ (provided, of course, that $\left.t+1<\bar{u}_{j}\right)$ and a positive probability that the next sincere bid satisfies $x_{j}(t+1)<\varepsilon$, for every $\varepsilon>0$. If the full support assumption holds for all bidders $j \neq i$, then every bid by bidder $i$ matters. ${ }^{20}$ The next theorem shows that, under private values, incomplete information and the full support assumption, sincere bidding is the unique outcome of iterated weak dominance:

\footnotetext{
${ }^{18}$ With full bid information and under complete information regarding bidders' valuations, this statement simplifies to saying that sincere bidding by every bidder is a subgame perfect equilibrium.

${ }^{19}$ If, instead of being drawn independently, the utility functions of the bidders are drawn from a joint probability distribution, then the analogous condition can be required on the marginal distribution for bidder $i$, given any realization for bidders $-i$.

${ }^{20}$ Conversely, suppose in an example similar to that of Table 1, that Bidder D's marginal value for a second unit equals 65 but that there is zero probability that any opposing bidder's marginal value is anywhere in the interval [60,70]. Then sincere bidding is not quite mandated: it is irrelevant to Bidder D's payoff at which price in $[60,70]$ she reduces her quantity from 2 to 1 .
} 
THEOREM 2. Under private values, incomplete information and the full support assumption, sincere bidding by all bidders is the unique outcome of iterated elimination of weakly dominated strategies in the alternative ascending-bid auction. ${ }^{21}$

Observe the following special cases of Theorem 2. For a single item, sincere bidding is the unique outcome of iterated weak dominance in the English auction. For $M$ identical items and bidders with unit demands, sincere bidding is the unique outcome of iterated weak dominance in the uniform-price ascending auction. Both of these special cases obviously also require the full support assumption, which specialized to these cases is simply the requirement that the support of $u_{i}(1)$ is a set $\left\{0, \ldots, \bar{u}_{i}\right\}$.

One other observation is worth making at this juncture. The reason that we are able to obtain exactly the Vickrey outcome (as opposed to merely an approximation) in the discrete auction game is our assumption that all marginal valuations are integers. As a consequence, all payments in the Vickrey auction are integers, and there is no loss of information in only eliciting bids at integer prices. However, in the interdependent values model of the next section, marginal valuations may take any nonnegative real values, so it is then necessary to utilize a continuous game in order to obtain full efficiency.

\section{Results in a Continuous-Time Game with Symmetric, Interdependent Values}

Among the most famous results in the single-item auction literature is the comparison between the second-price auction (a static auction) and the English auction (the associated dynamic auction) in a symmetric model with affiliated values. Each format exhibits an efficient equilibrium, but the efficient equilibrium of the dynamic auction yields higher expected revenues than that of the static auction (Milgrom and Weber, 1982a). ${ }^{22}$ The analogous comparison, for auctions of multiple identical objects, is the comparison between the Vickrey auction and the alternative ascending-bid auction of this paper. We find in this section that, in a symmetric model with flat demands and affiliated values, the dynamic auction has two advantages over the static auction. First, exactly as in Milgrom and Weber's analysis, the dynamic auction provides greater linkage between the payment and the bidders' signals, increasing the seller's expected revenues. Second, a "Generalized Winner's Curse" emerges that is not present in the single-item analysis, adversely affecting the efficiency of the static auction.

A seller offers $M$ discrete (and indivisible) units of a homogeneous good. The $n$ bidders have "flat demands": each bidder $i$ obtains constant marginal utility of $V_{i}$ from each of up to $\lambda_{i}$ units of the good, but zero marginal utility from any more than $\lambda_{i}$ units, where the capacity $\lambda_{i}$ satisfies $0<\lambda_{i} \leq M$. Let the capacities be sufficiently large that there is competition for every unit of the good (i.e., $\sum_{j \neq i} \lambda_{j} \geq M$ ). The marginal values $V_{i}(i=1, \ldots, n)$ are assumed to derive from affiliated signals. Let $S \equiv\left(S_{1}, \ldots, S_{n}\right)$ be a vector of $n$ real-valued signals which are privately observed by the $n$ respective bidders. Also let $S_{-i}$ denote the $(n-1)$ signals other than that observed by bidder $i$, without the identities of the individual bidders indicated. Following Milgrom and Weber (1982a), it will be assumed that:

\footnotetext{
${ }^{21}$ Elimination or iterated elimination of weakly dominated strategies is sometimes criticized on account that its outcome may depend on the order of elimination. However, observe that Theorem 2 demonstrates order independence in this particular context.

${ }^{22}$ Milgrom and Weber (1982a) also compare the sealed-bid first-price auction of a single item. For a comparison involving the pay-as-bid auction (the multi-unit version of the first-price auction), see Ausubel and Cramton (2002).
} 
(A.1) $V_{i}=v\left(S_{i}, S_{-i}\right)$, where $v(\bullet)$ is the same nonnegative-valued function for every bidder $i$ $(i=1, \ldots, n), v(\bullet)$ is continuous in all its arguments, $v(\bullet)$ is strictly increasing in its first argument, and $v(\bullet)$ is nondecreasing in its remaining arguments. ${ }^{23}$

(A.2) $E\left[V_{i}\right]<\infty$, for every bidder $i(i=1, \ldots, n)$.

(A.3) The variables $\left(S_{1}, \ldots, S_{n}\right)$ are affiliated.

(A.4) The joint density, $f(\bullet, \ldots, \bullet)$, of $\left(S_{1}, \ldots, S_{n}\right)$ is symmetric in its arguments.

Loosely speaking, the affiliation assumption (A.3) requires that the agents' signals, $S_{i}$, be nonnegatively correlated with one another. More precisely, let $s$ and $s^{\prime}$ be possible realizations of $\left(S_{1}, \ldots, S_{n}\right)$. Let $s \vee s^{\prime}$ and $s \wedge s^{\prime}$ denote their componentwise maximum and minimum, respectively. We say that $\left(S_{1}, \ldots, S_{n}\right)$ are affiliated if $f\left(s \vee s^{\prime}\right) f\left(s \wedge s^{\prime}\right) \geq f(s) f\left(s^{\prime}\right)$, for all $s$ and $s^{\prime}$ (see Milgrom and Weber, 1982a, p. 1098).

It will often be helpful to let $S_{-i j}$ denote the (n-2)-tuple of signals received by bidders other than $i$ and $j$, and to also assume:

$$
V_{i}=v\left(S_{i}, S_{j}, S_{-i j}\right)>v\left(S_{j}, S_{i}, S_{-i j}\right)=V_{j} \text { whenever } S_{i}>S_{j} .
$$

In order to accommodate full separation by bidders in their signals - which is necessary for efficiency in a model with a continuum of signals - we change our model to a continuous-time game. But, once going to a continuous-time game, we need to treat the possibility that bidder $i$ 's strategy may be to reduce her quantity at a given time, while bidder $j$ 's strategy may be to reduce his quantity at the soonest possible instant after bidder $i$ reduces her quantity. Ideally, we should allow "moves that occur consecutively but at the same moment in time" (Simon and Stinchcombe, 1989, p. 1181).

The game may thus be conceptualized by thinking of "time" as being represented by a pair, $(t, r)$, where $t$ is given by a continuous ascending clock and $r$ is given by an implicit discrete ascending counter. Times are ordered lexicographically: first in $t$; and second in $r$. Generally speaking, the clock time $t$ increments continuously, and each bidder is free to reduce her quantity at any clock time. However, if bidder $i$ reduces her quantity at a given clock time $t$, bidder $j$ is allowed to respond by reducing his quantity at the same clock time $t$ (but, nevertheless, after bidder $i$ 's move). This is the role of the counter $r$ : if bidder $i$ reduces her quantity at $(t, r)$, the next available time which follows is $(t, r+1)$. Each time that some bidder reduces her quantity, the counter increments instead of the clock; and when players have finished reducing their quantities at the current clock time, the clock restarts instead.

Whenever the clock is ascending, we shall make full use of the continuous-time framework by specifying that price is a continuous and strictly-increasing function of time, and in fact, for simplicity, $d p / d t=1$. However, there is no conceptual or game-theoretic reason why the clock needs to restart at the

\footnotetext{
${ }^{23}$ As noted by Milgrom and Weber (1982a, p. 1100), the "nondegeneracy assumption" that a bidder's expected value is strictly increasing in her own signal is unnecessary for the results to hold, but greatly simplifies the proofs.
} 
same price as where it stopped and, in fact, we have considerable latitude in specifying the price at which the clock restarts. We shall consider two variations on the continuous-time auction rules: $:^{24}$

STOPPING THE CLOCK: Whenever a bidder reduces her quantity demanded, the price clock pauses to enable other quantity reductions. The clock then resumes its ascent, restarting at the same price where it stopped, so that $p(t)=t$.

TURNING BACK THE CLOCK: The same procedure is followed as in "stopping the clock." However, whenever any bidder reduces her quantity to zero, the price clock is restarted at zero, so that $p(t)=t-t_{0}$, where $t_{0}$ is the most recent time at which some bidder has reduced to zero. ${ }^{25}$

There will be no confusion if we suppress the implicit counter $r$ from our notation. Any history of the auction game can be uniquely summarized by a finite string of pairs: $h \equiv\left(t^{0} ; x^{0}\right), \ldots,\left(t^{L} ; x^{L}\right)$. Each $t^{\ell}$ denotes the time of the $\ell^{\text {th }}$ occasion on which one or more bidders strictly decreased her quantity, and each $x^{\ell}$ denotes the vector of quantities demanded by bidders $1, \ldots, n$ beginning at that occasion. Since quantities are discrete, and given the monotone activity rule, the length of any history $h$ is bounded by the number of objects. Together with the current time, $h$ fully summarizes the prior play of the game. ${ }^{26}$ Further, let $x_{i}(h)$ denote bidder $i$ 's current quantity and let $C_{i}(h)=M-\sum_{j \neq i} x_{j}(h)$ denote bidder $i$ 's cumulative clinches after history $h$.

Let $s_{i}$ denote the realization of the private signal $S_{i}$ received by bidder $i$ and let $h_{i}$ denote the summary of the history which is made observable to bidder $i$. A pure strategy for bidder $i$ is a pair of functions, $\beta_{i}\left(s_{i}, h_{i}\right)$ and $\gamma_{i}\left(s_{i}, h_{i}\right)$, of private signals and observable summaries of the history. Then $\beta_{i}\left(s_{i}, h_{i}\right)$ provides the earliest price at which bidder $i$ will decrease her demand, and $\gamma_{i}\left(s_{i}, h_{i}\right)$ provides the quantity to which she will decrease her demand, under the hypothesis that no opposing bidder $j$ reduces his own quantity first. (It need not indicate what bidder $i$ will do if some opposing bidder does reduce his quantity first, since then the history changes from $h$ to $h^{\prime}$, and so bidder $i$ would instead play according to $\left(\beta_{i}\left(s_{i}, h_{i}^{\prime}\right), \gamma_{i}\left(s_{i}, h_{i}^{\prime}\right)\right)$. The function $\gamma_{i}\left(s_{i}, h_{i}\right)$ is restricted to generate bids that are consistent

\footnotetext{
${ }^{24}$ An insightful, anonymous referee has pointed out that the "turning back the clock" variation on the auction rules may open the door to the following form of anticompetitive bidder behavior. Consider an auction for two identical objects $(M=2)$, with two real bidders, 1 and 2, each having capacity for both objects $\left(\lambda_{1}=2=\lambda_{2}\right)$. Bidder 1 might enter an additional "shill" bidder 3 (with $\lambda_{3}=2$ ) to bid on its behalf. Bidders 1 (and 3) wait for Bidder 2 to drop out of the auction. Then, after the price restarts at zero, the shill Bidder 3 drops out of the auction, allowing Bidder 1 to win both objects at a price of $\varepsilon$. Note that this shill-bidding strategy is violative of the rules of most auctions (e.g., the FCC auctions) with which the author is familiar, and probably also violative of U.S. antitrust law. Typically, a "bidder" (defined as any entity entering into the auction) is not permitted to collude (or bid jointly) with another "bidder"; moreover, two associated bidders are typically not permitted to enter into the auction and bid on the same items. Nevertheless, this example makes quite clear that the "turning back the clock" variation should not be used in any real-world situation where the auctioneer may lack the ability to detect or enforce rules against collusion or shill bidding.

${ }^{25}$ In the working paper version (Ausubel, 1997), arbitrary restarting prices were allowed as a function of the history, in the "turning back the clock" variation. Here, we restrict attention to restarting prices of zero, in order both to simplify the exposition and to limit the information about the bidders' distributions that needs to be known by the auctioneer.

${ }^{26}$ To see the richness of the histories that this framework and notation allow, consider the history $h=(0 ; 3,2,2,2),(15 ; 3,1,2,2)$, $(15 ; 3,1,2,0),(27 ; 3,0,2,0)$. This should be interpreted as saying that Bidders A-D began by bidding 3, 2, 2 and 2, respectively. At a price of 15, Bidder B reduced from 2 units to 1 . Immediately after-and at the same price of 15-Bidder D responded by reducing from 2 units to 0 . The interpretation of the remaining point in history $h$ depends on whether we are using the "stopping the clock" or the "turning back the clock" variation. With stopping the clock, $p(27)=27$, meaning that Bidder B reduced from 1 unit to 0 at a price of 27. With turning back the clock, $p(27)=27-15=12$ (since $t=15$ is the most recent time at which some bidder has reduced to zero), meaning that Bidder B reduced from 1 unit to 0 at a price of 12 .
} 
with the monotone activity rule and that are never bids for fewer units than have been already clinched. Payments are defined analogously as in Section 2.

For bidders with private values (that is, $V_{i}=v\left(S_{i}\right)$ ), Theorems 1 and 2 continue to hold in the continuous-time framework of this section. Theorem 2 is established in this framework by: first, eliminating all strategies except sincere bidding following histories such that the aggregate demand of all bidders equals $M+1$; then, eliminating all strategies except sincere bidding following histories such that the aggregate demand of all bidders equals $M+2$; etc. The proofs are omitted from the paper.

For bidders with interdependent values (that is, $V_{i}=v\left(S_{i}, S_{-i}\right)$ nontrivially depends on $S_{-i}$ ), the analysis dichotomizes into two cases: ${ }^{27}(1)$ bidders have identical capacities $\left(\lambda_{i}=\lambda\right)$ and the number of available items is an integer multiple of the bidders' capacities; and (2) bidders' capacities are unequal or the number of available items is not an integer multiple of the bidders' capacities. The intuitive explanation for the difference between these two cases is that when $m \equiv M / \lambda$ is an integer, the model is closely related to one in which bidders possess unit demands and compete for $m$ indivisible objects. There, symmetric equilibria with flat bid functions exist, yielding full efficiency. However, when $m \equiv M / \lambda$ is not an integer or the $\lambda_{i}$ are not equal, symmetric equilibria with flat bid functions no longer exist.

First, in the case where $M / \lambda$ is an integer, the static and dynamic auctions both have efficient equilibria but, due to the affiliated values, the expected revenues of the dynamic auction are greater:

THEOREM 3. Let the bidders have identical capacities, $\lambda$, and let $m \equiv M / \lambda$ be an integer. Then in a symmetric model with interdependent values satisfying (A.1)-(A.4), both the Vickrey auction and the alternative ascending-bid auction have efficient equilibria. Each attains full efficiency, but the alternative ascending-bid auction raises expected revenues the same as or higher than the Vickrey auction. ${ }^{28}$

However, in the case where $M / \lambda$ is not an integer, or the $\lambda_{i}$ are not equal, the static auction does not admit efficient equilibria in the interdependent values models, while the dynamic auction possesses an efficient equilibrium. The intuition for the result is a generalization of the standard "Winner's Curse" for single-object auctions: in a symmetric, multi-unit auction with interdependent values, a bidder's expected value conditional on winning more objects is less than her expected value conditional on winning fewer objects. The static auction does not allow bidders to account for the generalized Winner's Curse without impairing efficiency, while the dynamic auction does. We have:

THEOREM 4. Let the bidders either have identical capacities $\lambda$, where $M / \lambda$ is not an integer, or have unequal capacities $\lambda_{i}$. Then in a symmetric model with interdependent values satisfying (A.1)-(A.5), all equilibria of the Vickrey auction are inefficient, but the alternative ascending-bid auction possesses an efficient equilibrium. Moreover, if bidders' signals are independent, then the alternative ascending-bid auction raises strictly higher expected revenues than the Vickrey auction. ${ }^{29}$

\footnotetext{
${ }^{27}$ This dichotomy parallels our analysis of the uniform-price auction in Ausubel and Cramton (2002).

${ }^{28}$ Theorem 3 holds regardless of whether the rule governing the price process is "stopping the clock" or "turning back the clock."

${ }^{29}$ Theorem 4 requires that the rule governing the price process is "turning back the clock."
} 
If bidders' signals are independent, then, in the "flat demands" model studied in this section, revenue maximization uniquely coincides with efficiency (Ausubel and Cramton, 1999, Proposition 1). Consequently, the third sentence of Theorem 4 follows from the second sentence of Theorem 4 . It is an open question whether this revenue ranking extends to flat demands in a symmetric model where signals are strictly affiliated.

At the same time, Theorem 4 should not be misinterpreted to suggest that there does not exist any efficient static mechanism in this environment. Indeed, in Appendix B of the working paper version (now a separate paper, Ausubel, 1999), as well as in Jehiel and Moldovanu (2001) and Perry and Reny (2002), an efficient direct mechanism is derived. Rather, the correct interpretation of Theorem 4 is merely that the rules of the standard Vickrey auction do not allow efficiency in the face of value interdependencies.

\section{Conclusion}

This article has proposed a new ascending-bid auction for multiple objects. In an environment where bidders have pure private values, the new dynamic auction exhibits an efficient equilibrium corresponding to that of a classic sealed-bid auction, the multi-unit Vickrey auction; and for some formalizations of the game, the efficient equilibrium is generated by an iterated dominance argument. In an environment where bidders have interdependent values and a multi-unit generalization of the Milgrom and Weber (1982a) assumptions is satisfied, the new dynamic auction continues to exhibit an efficient equilibrium, whereas all equilibria of the standard sealed-bid auctions are inefficient.

The notion that the alternative ascending-bid auction may be simpler than the Vickrey auctionwhile motivated by single-item experiments and by practical experience-is not explicitly modeled here. However, in the time since I proposed the auction, three sets of researchers have run laboratory experiments involving the new dynamic auction, enabling us to begin to see the comparison between static and dynamic auctions in experimental settings.

Kagel and Levin (2001) and Kagel, Kinross and Levin (2001) have tested my auction using a clever experimental design in which human subjects play against computers. A seller has two identical objects for sale to bidders with private values. In each trial, one bidder has a flat demand for two units; and the remaining $(n-1)$ bidders have demand for only one unit. Computers replace the one-unit bidders, who have dominant strategies; while the experimental subjects play the role of two-unit bidder. Kagel and Levin compare two versions of the uniform-price auction - a sealed-bid and an ascending-clock uniformprice auction - with the current auction. As the theory predicts, they observe clear and unambiguous demand reduction in the uniform-price auctions, with demand reduction sharply limited in my auction. Consequently, more than $99 \%$ of the predicted gains from trade, and essentially exactly the predicted revenues, are observed. Kagel, Kinross and Levin compare the (sealed-bid) Vickrey auction with two versions of my auction- "with dropout information" (the full bid information specification, which is solvable by iterated weak dominance) and "without dropout information" (the no bid information specification, which is solvable by a single round of weak dominance). They conclude (pp. 22-23): 
Our main finding is that behavior in the Ausubel auction with dropout information comes closer to sincere bidding than behavior in either the sealed-bid Vickrey auction or the Ausubel auction without dropout information, even though the auction with dropout information involves a weaker solution concept than the other two. ... Our main finding suggests a tradeoff between a mechanism that simplifies agents' decision task versus one that relies on a stronger solution concept when the two do not coincide. The tradeoff seems to lie in the fact that transparency is valued by boundedly rational agents, so that it may more than offset the additional strategic ambiguity that may arise due to a weaker solution concept.

Interestingly, and counter to the theory, Kagel, Kinross and Levin also find that seller revenues are significantly higher in the Vickrey auction than in my auction, due to more frequent overbidding.

Grimm and Engelmann (2002) consider auctions of two identical objects, experimentally comparing five formats: a sealed-bid uniform-price auction; an ascending-bid uniform-price auction; a pay-as-bid auction; a Vickrey auction; and the alternative ascending-bid auction. Similar to Kagel and his co-authors, they find that my design achieves the highest allocative efficiency and they conclude (p. 23):

If the primary aim is the efficient allocation, the Ausubel auction seems to be best suited, while if the focus is on revenues, the sealed-bid auctions perform best due to frequent overbidding in the case of the uniform price auctions and to bids generally exceeding equilibrium bids in the discriminatory auction. A mechanism that is easy to understand seems best suited to allocate the units efficiently, while one where optimal strategies are difficult to figure out may be better to maximize revenues. The latter, of course, also involve more risks for the auctioneer.

Manelli, Sefton and Wilner (1999) experimentally compare the Vickrey auction with my auction, using bidders with interdependent values in some of their tests. A seller has three identical objects for sale to bidders with flat demands for two units each. The bidders receive independent signals, but in the interdependent values setting, each bidder's value is a weighted average of her own and her opponents' signals. The authors report (p. 3): "As in the single-unit English auction, participants in the Ausubel mechanism seem to understand the consequences of overbidding better than participants in the Vickrey mechanism. Nonetheless, bidders in the Ausubel auction engage in a particular type of 'overbidding,' strategic in nature." ${ }^{30}$ As a result, the authors report evidence of a "potential tradeoff between efficiency and revenue. The Vickrey auction achieves higher efficiency but yields lower revenue than the Ausubel auction." Observe that this result, in Manelli, Sefton and Wilner's setting, goes the opposite direction on both efficiency and revenues as the two previous sets of results.

My paper has only treated interdependent values in a very limited way. While the formulation of Section 4 is a strict generalization of the classic Milgrom and Weber (1982a) single-object model, it nevertheless restricts attention to economic environments that are symmetric across bidders and objects. Some other authors have since obtained more general auction results for interdependent values. Perry and Reny (2001) show that, with two bidders, my auction continues to yield efficient outcomes in a general specification of interdependent values based on one-dimensional signals. They further show that by expanding the procedure to allow bidders to submit directed demands (one against each other bidder), it is

\footnotetext{
${ }^{30}$ Some of the experimental subjects bid for three units, despite holding a positive marginal value for only two units.
} 
possible to obtain efficient outcomes with $n$ bidders, identical objects, and interdependent values based on one-dimensional signals. Dasgupta and Maskin (2000) construct a static auction that yields efficient outcomes with $n$ bidders, heterogeneous objects, and interdependent values based on one-dimensional signals. For every set of objects, a buyer submits a bid correspondence specifying her willingness to pay given every possible vector of rivals' valuations for every possible set of objects. ${ }^{31}$ The auctioneer then solves a fixed-point problem in the submitted bids and uses the solution to efficiently assign the objects. Thus, the more general interdependent values environments with one-dimensional signals are completely and efficiently treated, at the expense of a more complicated auction procedure. Whether experimental subjects come close to bidding sincerely in (or are even able to understand) the more general treatments is an important question for future research, which may help to clarify our view of the best auction design.

Finally, the current paper and most other recent work on efficient dynamic auctions of multiple items has restricted attention to homogeneous goods. In Ausubel (2002), I expand the environment to allow bidders with concave utilities over heterogeneous commodities and I generalize the auction procedure herein. Subject to a few caveats, I conclude there that it is still possible to replicate the outcome of the Vickrey-Clarke-Groves mechanism with a dynamic auction procedure.

\footnotetext{
${ }^{31}$ Perry and Reny (2002, p. 1199) interpret this as requiring each bidder to report "the set of all possible preferences of all bidders that are consistent with his private information."
} 


\section{References}

Ausubel, Lawrence M, “An Efficient Ascending-Bid Auction for Multiple Objects.” Working Paper No. 97-06, University of Maryland, Department of Economics, June 1997.

Ausubel, LAWrence M, “A Generalized Vickrey Auction.” Mimeo, University of Maryland, September 1999.

Ausubel, Lawrence M., "System and Method for an Efficient Dynamic Auction for Multiple Objects." U.S. Patent Number 6,026,383, filed January 4, 1996; issued February 15, 2000.

Ausubel, LaWrence M, “An Efficient Dynamic Auction for Heterogeneous Commodities." Mimeo, University of Maryland, July 2002.

Ausubel, Lawrence M. And Peter C. Cramton, "The Optimality of Being Efficient." Mimeo, University of Maryland, June 1999.

Ausubel, Lawrence M. and Peter C. Cramton, "Demand Reduction and Inefficiency in Multi-Unit Auctions." Working Paper No. 96-07, University of Maryland, Department of Economics, July 2002 revision.

Ausubel, Lawrence M. And Paul Milgrom, “Ascending Auctions with Package Bidding.” Mimeo, University of Maryland and Stanford University, July 2002.

Ausubel, Lawrence M. And Jesse Schwartz, "The Ascending Auction Paradox." Mimeo, University of Maryland and Vanderbilt University, July 1999.

BACK, KeRRY AND JAIME F. ZENDER, “Auctions of Divisible Goods: On the Rationale for the Treasury Experiment." Review of Financial Studies, Winter 1993, 6(4), pp. 733-764.

BIKHCHANDANI, SUSHIL, "Auctions of Heterogeneous Objects." Games and Economic Behavior, January 1999, 26(2), pp. 193-220.

BikHChandani, Sushil, SVEn DE VRIES, JAmes Schummer AND RAKesh V. Vohra, "Linear Programming and Vickrey Auctions." Mimeo, UCLA and Northwestern University, May 2001.

BIKHCHANDANI, SUSHIL AND JOHN W. MAMER, "Competitive Equilibrium in an Exchange Economy with Indivisibilities.” Journal of Economic Theory, June 1997, 74(2), pp. 385-413.

Bikhchandani, Sushil and Joseph M. Ostroy, “Ascending Price Vickrey Auctions.” Mimeo, UCLA, September 2001.

CASSADY, RalPh, JR., Auctions and Auctioneering. Berkeley: University of California Press, 1967.

Cramton, Peter C., "Money Out of Thin Air: The Nationwide Narrowband PCS Auction." Journal of Economics and Management Strategy, Summer 1995, 4(2), pp. 267-343.

DASGUPTA, PARTHA AND ERIC S. MASKIn, "Efficient Auctions." Quarterly Journal of Economics, May 2000, 115(2), pp. 341-388.

Demange, Gabrielle, David Gale, And Marilda Sotomayor, "Multi-Item Auctions." Journal of Political Economy, August 1986, 94(4), pp. 863-872.

Engelbrecht-Wiggans, Richard and Charles M. Kahn, "Protecting the Winner: Second-Price versus Oral Auctions.” Economics Letters, March 1991, 35(3), pp. 243-248.

Grimm, VERONIKA AND DIRK ENGELMANN, "Bidding Behavior in Multi-Unit Auctions-An Experimental Investigation.” Working Paper, Humboldt-Universität zu Berlin, February 2002.

Gul, FARUK AND ENNIO STACChETTI, "Walrasian Equilibrium with Gross Substitutes." Journal of Economic Theory, July 1999, 87(1), pp. 95-124.

Gul, FARUK AND ENNIO STACCHETTI, "The English Auction with Differentiated Commodities." Journal of Economic Theory, May 2000, 92(1), pp. 66-95.

Jehiel, Philippe And Benny Moldovanu, "A Critique of the Planned Rules for the German UMTS/IMT-2000 License Auction.” Mimeo, University of Mannheim, March 2000. 
Jehiel, Philippe AND Benny Moldovanu, "Efficient Design with Interdependent Valuations." Econometrica, September 2001, 69(5), pp. 1237-1259.

KAGEL, JOHN H., RonAld M. HARSTAD AND DAN LEVIN, "Information Impact and Allocation Rules in Auctions with Affiliated Private Values: A Laboratory Study." Econometrica, November 1987, 55(6), pp. 1275-1304.

Kagel, John H., Scott KinRoss and Dan Levin, "Comparing Efficient Multi-Object Auction Institutions.” Working Paper, Ohio State University, August 2001.

Kagel, John H., AND DAN Levin, "Behavior in Multi-Unit Demand Auctions: Experiments with Uniform Price and Dynamic Vickrey Auctions.” Econometrica., March 2001, 69(2), pp. 413-454.

Kelso, AleXander S. AND Vincent P. CRAWFORD, "Job Matching, Coalition Formation, and Gross Substitutes.” Econometrica, November 1982, 50(6), pp. 1483-1504.

Krishna, ViJAY AND MotTy PERry, "Efficient Mechanism Design.” Mimeo, Penn State University and Hebrew University, April 1998.

Maneldi, Alejandro M., Martin Sefton and Benjamin S. Wilner, "Multi-Unit Auctions: A Comparison of Static and Dynamic Mechanisms." Working Paper, Arizona State University, University of Newcastle and LECG/Navigant Consulting, October 1999.

MASKIN, ERIC S., "Auctions and Privatization," in Horst Siebert, ed., Privatization: Symposium in Honor of Herbert Giersch. Tubingen: Mohr (Siebeck), 1992, pp. 115-136.

MASKIn, ERIC S. AND JOHN G. RILEY, "Optimal Multi-unit Auctions," in Frank Hahn, ed., The Economics of Missing Markets, Information, and Games. Oxford: Oxford University Press, 1989, pp. 312-35.

McAfee, R. Preston AND John McMillan, “Auctions and Bidding." Journal of Economic Literature, June 1987, 25(2), pp. 699-738.

MCMillan, JoHn, “Selling Spectrum Rights.” Journal of Economic Perspectives, Summer 1994, 8(3), pp. 145-162.

Milgrom, Paul R., "Auction Theory," in Truman F. Bewley, ed., Advances in Economic Theory Fifth World Congress. Cambridge: Cambridge University Press, 1987, pp. 1-32.

Milgrom, Paul R., "Putting Auction Theory to Work: The Simultaneous Ascending Auction." Journal of Political Economy, April 2000, 108(2), 245-272.

Milgrom, Paul R. AND Robert J. Weber, "A Theory of Auctions and Competitive Bidding." Econometrica, September 1982a, 50(5), pp. 1089-1122.

Milgrom, Paul R. AND Robert J. Weber, "A Theory of Auctions and Competitive Bidding, II." Unpublished manuscript, Northwestern University, 1982b.

Perry, MotTy And PhiliP J. Reny, “An Efficient Multi-Unit Ascending Auction.” Working Paper, Hebrew University and University of Chicago, May 2001.

Perry, Motty And PhiliP J. RenY, “An Efficient Auction.” Econometrica, May 2002, 70(3), pp. 1199-1212.

Rothkopf, Michael H., Thomas J. Teisberg, and Edward P. Kahn, "Why Are Vickrey Auctions Rare?" Journal of Political Economy, February 1990, 98(1), pp. 94-109.

Simon, Leo K. And MaXwell B. Stinchcombe, "Extensive Form Games in Continuous Time: Pure Strategies.” Econometrica, September 1989, 57(5), pp. 1171-1214.

Vickrey, William, "Counterspeculation, Auctions, and Competitive Sealed Tenders." Journal of Finance, March 1961, 16(1), pp. 8-37.

WiLSON, ROBERT, “Auctions of Shares." Quarterly Journal of Economics, November 1979, 93(4), pp. 675-689. 


\section{Appendix}

PROOF OF THEOREM 1.

At every point in the alternative ascending-bid auction up until its end, all of the payoff-relevant events in the auction occur through clinching. The cumulative quantity of clinched units for bidder $i$ at time (and price) $t$ is given by Eqs. (2)-(3). Observe that the right side of Eq. (2) is independent of bidder $i$ 's actions; hence, changing one's own bid strategy can have no effect on payoff, except to the extent that: (i) it leads rival bidders to respond; or (ii) it determines one's own final quantity $x_{i}^{*}$.

Since marginal utilities were assumed (weakly) diminishing, the sincere bidding strategy given by Eq. (7) always yields monotonically nonincreasing quantities over time. Moreover, sincere bidding by bidder $i$ always yields a final price $p^{*}$ and final quantity $x_{i}^{*}$ satisfying $x_{i}^{*} \in \underset{x_{i} \in X_{i}}{\arg \max }\left\{U_{i}\left(x_{i}\right)-p^{*} x_{i}\right\}$.

If all rival bidders $j \neq i$ bid sincerely, then rivals never respond to bidder $i$ 's strategy, except through price. Hence, sincere bidding is a mutual best response for every bidder-for every realization of utilities and after every history - and hence it is an ex post perfect equilibrium. Given the sincere bids of Eq. (7) and the payoff Eq. (6), it always yields the efficient outcome of the Vickrey auction. Moreover, with no bid information, a rival cannot distinguish between two strategies of bidder $i$, except to the extent that one or the other ends the auction. Hence, changing one's own bid strategy cannot lead rivals using any strategy to respond. We conclude that sincere bidding is a weakly dominant strategy in the auction with no bid information.

\section{PROOF OF THEOREM 2.}

First, we provide an order of elimination that yields sincere bidding as the outcome of iterated weak dominance. We begin with the last period, $T$. Since bidders' marginal valuations are assumed to be bounded by $\bar{u}<T$, each bidder wishes to minimize the number of units won at time $T$. Given that the rationing rules in case of over- or under-subscription are monotonically increasing in the final bids (see footnotes 14 and 15), the sincere bids $x_{i}^{T}=C_{i}^{T-1}$ weakly dominate all insincere bids $x_{i}^{T}>C_{i}^{T-1}$, and so all strategies specifying insincere bids at time $T$ can be eliminated. Now suppose that with $k$ iterations of weak dominance, all strategies other than sincere bidding have already been eliminated at times $t=T-k+1, \ldots, T$. Then the choice of $x_{i}^{T-k}$ can have no effect on the subsequent bidding by opponents. By the full support assumption, there is a positive probability that bidder $i$ 's opponents have valuations leading them each: (i) to bid this period in a neighborhood of their maximum allowable bids, i.e., $x_{j}^{T-k}>x_{j}^{T-k-1}-\varepsilon$, for all $j \neq i$; and (ii) to bid next period in a neighborhood of their minimum allowable bids, i.e., $x_{j}^{T-k+1}<C_{j}^{T-k}+\varepsilon$, for all $j \neq i$. If $x_{i}^{T-k}$ is greater than bidder $i$ 's sincere demand, then in this event (and again using the fact that the rationing rules are monotonically increasing in the final bids; see footnotes 14 and 15), bidder $i$ will unprofitably win units at time $T-k+1$ that he could have avoided winning by bidding sincerely at time $T-k$. Hence, all strategies specifying bids greater than the sincere demand at time $T-k$ can be eliminated. Also by the full support assumption, there is a positive probability that bidder $i$ 's opponents have valuations leading them each to bid this period in a neighborhood of their 
minimum allowable bids, i.e., $x_{j}^{T-k}<C_{j}^{T-k-1}+\varepsilon$, for all $j \neq i$. If $x_{i}^{T-k}$ is less than bidder $i$ 's sincere demand, then in this event (and also using the fact that the rationing rules are monotonically increasing in the final bids), bidder $i$ will unprofitably forego winning units in period $T$ that he could have won by bidding sincerely. Hence, all strategies specifying bids less than the sincere demand at time $T-k$ can be eliminated. By induction, all strategies specifying insincere bids at any time and after any history of the auction can be eliminated in $(T+1)$ iterations of weak dominance.

Second, we show that sincere bidding is the unique outcome of iterated weak dominance. First, sincere bidding is never eliminated. (Suppose otherwise. Consider the first round of elimination in which sincere bidding is eliminated for any type of any bidder, and let $\sigma_{i}$ denote the strategy that dominates it. In this round, sincere bidding by all types of all bidders $-i$ is still possible. Against sincere bidding by bidders $-i$, and given full support, one can always choose a realization of types for bidders $-i$ such that sincere bidding yields a higher payoff for bidder $i$ than does $\sigma_{i}$. This contradicts that sincere bidding could be eliminated.) Second, given this, and following the procedure of the previous paragraph, all strategies other than sincere bidding can be eliminated in $(T+1)$ more iterations of weak dominance, independent of the eliminations that have already occurred.

\section{An EfFicient Equilibrium of the Alternative Ascending-Bid Auction for the Symmetric} INTERDEPENDENT VALUES MODEL.

An equilibrium will be constructed so that every bidder $i$ bids up to her expected valuation, conditional on the lowest of the other active bidders' signals equaling her own signal. Upon reaching her expected valuation, she will drop to her lowest allowable quantity, $C_{i}(h)$. Since the bidding threshold is monotonically increasing in bidder $i$ 's signal $s_{i}$, for each equilibrium history $h$, bidders will drop out of the auction in (increasing) order of their signals $s_{i}$, as required for efficiency. Moreover, each bidder clinches units precisely in those situations where her expected value exceeds the clinching price, and she fails to clinch units precisely in those situations where her expected value is less than the clinching price, so each bidder maximizes her payoff against the opposing bidders' strategies.

For any bidder $i(i=1, \ldots, n)$, and for any $j(j=1, \ldots, n-1)$, let $Y_{j}^{-i}$ denote the $j^{\text {th }}$-order statistic of the signals received by all of the bidders excluding bidder $i$. Using the symmetry assumption A.4, the distribution of $Y_{j}^{-i}$ is independent of $i$, and so the superscript "- $i$ " will henceforth be suppressed from $Y_{j}^{-i}$. Given knowledge of the realizations of the order statistics $Y_{j}=y_{j}, \ldots, Y_{n-1}=y_{n-1}$, we may define:

$$
w_{j}\left(s, y ; y_{j}, \ldots, y_{n-1}\right)=E\left[V_{i} \mid S_{i}=s, Y_{j-1}=y, Y_{j}=y_{j}, \ldots, Y_{n-1}=y_{n-1}\right] \text {, for } j=2, \ldots, n \text {. }
$$

Without knowledge of the realizations of the order statistics, we may define the corresponding value:

$$
v_{j}(s, y)=E\left[V_{i} \mid S_{i}=s, Y_{j-1}=y\right] \text {, for } j=2, \ldots, n .
$$

Finally, let us define a bidder $i$ to be active after history $h$ if and only if $x_{i}(h)>C_{i}(h)$. Furthermore, define $J(h)=\left|\left\{i \in N: x_{i}(h)>C_{i}(h)\right\}\right|$ to be the cardinality of the set of active bidders after history $h$. Then $n-J(h)$ bidders have dropped out at history $h$. Let bidder $i$ be one of the remaining active bidders and suppose that the bidders who have dropped out correspond to the order statistics 
$Y_{J(h)}=y_{J(h)}, \ldots, Y_{n-1}=y_{n-1}$. We can define the equilibrium bidding threshold for any active bidder $i$ to be her expected value for the objects, conditional on the lowest of the other active bidders' signals equaling her own signal $s$ (and on the inferred realizations of $\left.Y_{J(h)}, \ldots, Y_{n-1}\right)$. Algebraically, this is expressed by:

$$
\beta_{i}\left(s_{i}, h\right)=w_{J(h)}\left(s_{i}, s_{i} ; y_{J(h)}, \ldots, y_{n-1}\right) \text { and } \gamma_{i}\left(s_{i}, h\right)=C_{i}(h) \text {, }
$$

where the realizations $y_{J(h)}, \ldots, y_{n-1}$ may be inferred, inductively, from the history $h$ and the equilibrium strategies. Note that no updated inference is drawn from an opponent reducing to $x_{j}>C_{j}(h)$.

\section{AN EFFICIENT EQUILIBRIUM OF THE VICKREY AUCTION WHEN $m=M / \lambda$ IS AN INTEGER.}

By similar reasoning, in the Vickrey auction, with $m=M / \lambda$ an integer, the following bidding strategy for each bidder, for all quantities $q=1, \ldots, \lambda$, and for all signals $s_{i}$, is an (efficient) equilibrium:

$$
b_{i}^{q}\left(s_{i}\right)=v_{m+1}\left(s_{i}, s_{i}\right), \text { for } i=1, \ldots, n .
$$

The strategy of Eq. (11) is almost the same as the bidding threshold of Eq. (10) evaluated at $J(h)=m+1$, except for the fact that the inferred realizations of $Y_{m+1}, \ldots, Y_{n-1}$ are unavailable in the Vickrey auction.

\section{PROOF OF THEOREM 3.}

If all $n$ bidders use the strategies defined by Eq. (11) (and using the symmetry assumed in A.1 and A.4), the seller's expected revenues in the Vickrey auction are given by $E\left[v_{m+1}\left(Y_{m}, Y_{m}\right) \mid S_{i}>Y_{m}\right]$. Meanwhile, if $m=M / \lambda$ is an integer and if all $n$ bidders use the strategies defined by Eq. (10), the seller's expected revenues in the alternative ascending-bid auction are given by $E\left[w_{m+1}\left(Y_{m}, Y_{m} ; Y_{m+1}, \ldots, Y_{n-1}\right) \mid S_{i}>Y_{m}\right]$. Closely following Milgrom and Weber (1982a, Theorem 8), we now demonstrate that the first quantity is no greater than the second quantity. Observe that, if $s>y$, then:

$$
\begin{aligned}
v_{m+1}(y, y) & =E\left[V_{i} \mid S_{i}=y, Y_{m}=y\right] \\
& =E\left[E\left[V_{i} \mid S_{i}=s, Y_{m}=y, Y_{m+1}=y_{m+1}, \ldots, Y_{n-1}=y_{n-1}\right] \mid S_{i}=y, Y_{m}=y\right] \\
& =E\left[w_{m+1}\left(S_{i}, Y_{m} ; Y_{m+1}, \ldots, Y_{n-1}\right) \mid S_{i}=y, Y_{m}=y\right] \\
& =E\left[w_{m+1}\left(Y_{m}, Y_{m} ; Y_{m+1}, \ldots, Y_{n-1}\right) \mid S_{i}=y, Y_{m}=y\right] \\
& \leq E\left[w_{m+1}\left(Y_{m}, Y_{m} ; Y_{m+1}, \ldots, Y_{n-1}\right) \mid S_{i}=s, Y_{m}=y\right] .
\end{aligned}
$$

Consequently, taking the conditional expectation of each side of this inequality, given $S_{i}>Y_{m}$, yields:

$$
\begin{aligned}
E\left[v_{m+1}\left(Y_{m}, Y_{m}\right) \mid S_{i}>Y_{m}\right] & \leq E\left[E\left[w_{m+1}\left(Y_{m}, Y_{m} ; Y_{m+1}, \ldots, Y_{n-1}\right) \mid S_{i}, Y_{m}\right] \mid S_{i}>Y_{m}\right] \\
& =E\left[w_{m+1}\left(Y_{m}, Y_{m} ; Y_{m+1}, \ldots, Y_{n-1}\right) \mid S_{i}>Y_{m}\right] .
\end{aligned}
$$

This inequality establishes that the seller's expected revenue from the static auction is no greater than from the dynamic auction, as required. 


\section{PROOF OF THEOREM 4.}

Suppose, to the contrary, that there exists an ex post efficient equilibrium of the Vickrey auction, but that $\lambda_{i} \equiv \lambda(i=1, \ldots, n)$ and $M / \lambda$ is not an integer. Let $m$ be the greatest integer such that $m \lambda<M$. By Lemma 1 of Ausubel and Cramton (2002), full efficiency requires that all bidders use the same flat bid function: there exists a strictly increasing function $\phi(\bullet)$ such that bidder $i$ bids $b_{i}^{q}\left(s_{i}\right)=\phi\left(s_{i}\right)$, for all $i=1, \ldots, n$, for all quantities $q=1, \ldots, \lambda$, and for almost every signal $s_{i}$. However, if all bidders use the same flat bid function, bidder $i$ 's bid for her first unit is $b_{i}^{1}\left(s_{i}\right)=v_{m+2}\left(s_{i}, s_{i}\right)$, since she wins 1 unit if and only if her signal is at least the $(m+1)^{\text {st }}$ order statistic of rivals' signals. Meanwhile, bidder $i$ 's bid for her last unit is $b_{i}^{\lambda}\left(s_{i}\right)=v_{m+1}\left(s_{i}, s_{i}\right)$, since she wins $\lambda$ units if and only if her signal is at least the $m^{\text {th }}$ order statistic of rivals' signals. Consequently, $b_{i}^{\lambda}\left(s_{i}\right)<b_{i}^{1}\left(s_{i}\right)$, contradicting the existence of an efficient equilibrium. If the $\lambda_{i}$ are unequal, similar reasoning can be applied to a bidder with maximum $\lambda_{i}$.

Meanwhile, the strategies defined by Eq. (10) provide an ex post efficient equilibrium of the alternative ascending-bid auction. 